\title{
Anthropometry based prediction of dominant hand grip strength in Indian office going females
}

\author{
S Rawat, L R Varte, I J Singh, S Choudhary, S Singh \\ Scientist " $D$ ", Anthropology Group, Defence Institute of Physiology and Allied Sciences, Defence Research \& \\ Development Organization, Ministry of Defence, Govt. of India, Lucknow Road, Timarpur, Delhi 110 054, India
}

Background: Physical strength can be measured by means of hand grip strength. It is of great use as a functional index of nutritional status. Aims and Objectives: Association of hand grip strength with other variables is studied in order to predict the strength outcomes and to study the effect of factors that can influence hand grip strength performance. Materials and Methods: In the present study the correlations of dominant hand grip strength and anthropometric and body composition variables namely, height, weight, forearm length, arm length, hand breadth, body mass index (BMI), and fat mass in randomly selected 375 unrelated, normal, healthy Indian office going females of age 20-60 years with mean height and weight of $154.12 \pm 5.94 \mathrm{~cm}$ and $59.86 \pm 10.94 \mathrm{~kg}$ respectively has been studied. Result: Hand grip strength of the females varied from $17 \mathrm{~kg}$ to $32 \mathrm{~kg}$ with a mean of $23.86 \pm 2.74 \mathrm{~kg}$. The comparison of age, height, weight, forearm length, arm length, hand breadth, and fat mass with the hand grip strength showed good correlation $(p<0.01)$. The best fit model for handgrip prediction when age, height, weight and hand breadth for this population were considered is Hand Grip $=-12.260-0.13 *$ Age $+0.16 *$ Height +0.13 * Weight $+1.02 *$ Hand breadth. Conclusion: It may be concluded that hand grip strength has close association with the anthropometric measurements and body composition variables and using these parameters grip strength can be predicted in Indian office going females.
Access this article online

Website:

http://nepjol.info/index.php/AJMS

DOI: 10.3126/ajms.v7i6.15197

E-ISSN: 2091-0576

P-ISSN: 2467-9100

Key words: Female anthropometry, Hand grip strength, Body composition

\section{INTRODUCTION}

Hand grip strength is an inevitable component in the evaluation of rheumatoid arthritis, neuromuscular, preoperative, post operative patients and community dwelling older adults' functional capacity. ${ }^{1}$ The estimation of handgrip strength is of immense importance in determining the efficacy of different treatment strategies of the hand and also in hand rehabilitation. ${ }^{2}$ Grip strength determines the handedness of an individual, an important field of population variation study. It is often used as an indicator of overall physical strength hand and forearm muscles performances and as a functional index of nutritional status and physical performance. ${ }^{3-9}$ Handgrip strength is a physiological variable that is affected by a number of factors including age, gender and body size. Strong correlations between grip strength and various anthropometric traits like weight, height, hand length etc. were reported earlier. ${ }^{10-13}$ Several studies have examined the relationships between anthropometric and physiological characteristics of volleyball players. ${ }^{14}$ Many daily functions and sporting events require high activity levels of the flexor musculature of the forearms and hands. These are the muscles involved in gripping strength. From sports like wrestling, tennis, football, basketball, and baseball to daily activities such as carrying laundry, turning a doorknob, and vacuuming, some degree of grip strength is necessary to be successful. For example, without adequate grip and forearm strength, tennis players may run the risk of developing lateral epicondylitis, otherwise known as tennis 
elbow. ${ }^{15}$ The strength of hand grip plays a key role in injury prevention and overall strength development ${ }^{15-17}$ with some researchers suggesting that grip strength be a screening tool for women at risk of osteoporosis. ${ }^{18}$ In order to properly diagnose various musculoskeletal deformities, especially related to upper extremities, and for their rehabilitation, the assessment of normative values for handgrip strength and its association with physical and body composition parameters is essential.

We hypothesize that there is strong relationship between anthropometry, body composition and hand grip strength of an individual. The purpose of this study was two-folds, firstly, to study the relation between handgrip strength and some anthropometric and body composition variables of Indian working females and, secondly, to predict dominant hand grip strength based on these parameters. The findings of the present study would be of great value in medical anthropology research, population genetics studies and in physical therapy treatment strategies.

\section{MATERIALS AND METHODS}

\section{Subjects}

Three hundred seventy five (375) women employees from seventeen Defence Research and Development Organisation (DRDO) laboratories volunteered as subjects. They were all physically fit. Females with any kind of physical deformity were excluded. The study was approved by institutional ethical committee and prior to the initiation of the study, subjects were informed about the purpose and methods of the study and their consent was taken.

Body measurements of the subjects were recorded as per the standard operating procedure. ${ }^{19}$ Anthropometric variables, i.e. height, weight and body mass index (BMI), hand breadth, forearm length, arm length, fat mass as body composition variables and dominant hand grip strength were measured.

The height was recorded during inspiration using SECA 767 electronic personal scale (Medical Scales and Measuring Systems, Germany) to the nearest $0.1 \mathrm{~cm}$, and weight was measured by Tanita TBF-310 Body composition analyzer (Tanita Corporation, Tokyo, Japan) to the nearest $0.1 \mathrm{~kg}$. Body mass index (BMI) is a measure of fatness, and is calculated by dividing the subject's weight in kilograms by height in meters squared $\left(\mathrm{kg} / \mathrm{m}^{2}\right)$. Hand breadth was measured by sliding caliper (Martin, GPM, Switzerland). Arm length and forearm length, was measured by the first segment of the anthropometer rod (Martin, GPM, Switzerland) and fat mass was measured using bio electric impedance analyser (Tanita TBF-310, Tanita Corporation,
Tokyo, Japan). These measurements were taken on the subject's right side.

The grip strength of dominant hand was measured using a standard adjustable digital handgrip dynamometer (Takei Scientific Instruments Co., LTD, Japan) at standing position with the shoulder adducted and neutrally rotated and elbow in full extension. The dynamometer was held freely without support, not touching the subject's trunk. The subjects were asked to put maximum force on the dynamometer from dominant hand twice, and 30 seconds break was given between the two trials. The maximum value was recorded in kilograms.

\section{Statistical methods}

Standard descriptive statistics (mean \pm standard deviation) were determined for directly measured and derived variables. Pearson's correlation coefficients were used to establish the correlations of dominant handgrip strength with anthropometric and body composition variables. Multiple regression analysis was further used to study the best fit model for handgrip prediction. Data were analyzed using Statistical Package for Social Science (version 11.5; SPSS Inc., Chicago, USA), in which the level of significance was set at $5 \%$.

\section{RESULTS}

Three hundred seventy five (375) working females participated in the study. Normative data pertaining to anthropometric characteristics, body composition and handgrip strength of Indian working females are shown in Table 1. The average female's height and weight were $154.12 \pm 5.94 \mathrm{~cm}$ and $59.86 \pm 10.94 \mathrm{~kg}$ respectively. The calculated average BMI from height and weight of the subjects was $25.28 \pm 4.34\left(\mathrm{~kg} / \mathrm{m}^{2}\right)$. The average handgrip strength measured from the 375 subjects was $23.86 \pm$ $2.74 \mathrm{~kg}$.

The correlation values and significance are depicted in the Table 2 . The findings of the present study indicated a significant positive association $(\mathrm{p} \leq 0.01)$ of dominant hand grip strength with the anthropometric parameters of upper extremities like forearm length $(\mathrm{r}=0.378)$, arm length $(\mathrm{r}=0.366)$ and hand breadth $(\mathrm{r}=0.466)$ and body composition variables like fat mass $(\mathrm{r}=0.458)$ and $\mathrm{BMI}$ $(\mathrm{r}=0.302)$. A significant negative association $(\mathrm{p} \leq 0.01)$ of age was found with the dominant hand grip strength in the present study.

\section{Multiple regression analysis}

The parameter estimates of the multiple regression analysis showed a significant positive association between dominant 
Table 1: Descriptive anthropometric, body composition and strength data $(\mathrm{n}=375)$

\begin{tabular}{llcr} 
S. no. & Parameter & Minimum & Mean \pm SD \\
\hline 1 & Age $(\mathrm{yrs})$ & 20.00 & 60.00 \\
2 & Height $(\mathrm{cm})$ & 135.30 & 172.60 \\
3 & Weight $(\mathrm{kg})$ & 34.60 & $154.12 \pm 5.94$ \\
4 & Hand grip strength $(\mathrm{kg})$ & 17.00 & 5.20 \\
5 & BMl $\left(\mathrm{Kg} / \mathrm{m}^{2}\right)$ & 16.00 & 32.00 \\
6 & Fat mass $(\mathrm{kg})$ & 3.20 & 41.10 \\
7 & Fat free mass $(\mathrm{kg})$ & 19.60 & 49.60 \\
8 & Forearm length $(\mathrm{cm})$ & 17.80 & 57.80 \\
9 & Arm length $(\mathrm{cm})$ & 35.40 & 32.60 \\
10 & Hand length & 13.50 & $18.90 \pm 7.53$ \\
11 & Hand breadth & 7.50 & $41.07 \pm 4.09$ \\
\hline
\end{tabular}

grip strength and height $(\mathrm{p}<0.001)$, weight $(\mathrm{p}<0.001)$ and hand breadth $(\mathrm{p}<0.001)$. Grip strength correlated negatively with age in a statistically significant manner $(p<0.001)$. The influence of fat mass, forearm length and arm length on grip strength was not found to be significant (Table 3). The best fit model for handgrip prediction when age, height, weight and hand breadth for this population were considered is

\section{Hand grip $=-12.260-0.13 *$ Age $+0.16 *$ Height $+0.13 *$ Weig ht $+1.02 *$ Hand breadth.}

A scatter plot was plotted between the predicted handgrip strength and the observed handgrip strength of this population (Figure 1) to study the validity of prediction equation. Mean handgrip strength using prediction equation was found to be $23.90 \pm 2.48 \mathrm{~kg}$ whereas observed mean grip strength was $23.86 \pm 2.74 \mathrm{~kg}$. Scatterplot (Figure 2) showed correlation of predicted handgrip strength to age, height, weight and hand breadth.

\section{DISCUSSION}

Although there are several studies examining the grip strength of different population groups the purpose of this study, specifically, were to establish a relation between handgrip strength and some anthropometric and body composition variables of Indian office working females and, secondly, to predict their dominant hand grip strength using linear regression analysis. ${ }^{16,20}$ As postulated by Bohannon et al (2006) it would be helpful to establish models on the basis of normative data to enable the prediction of a person's hand strength using quick and easy to measure parameters. ${ }^{20}$ The current study correlated age, anthropometric traits (height, weight, forearm length, arm length and hand breadth) and body composition parameters (BMI and fat mass) with dominant handgrip strength of Indian females. A statistically significant correlation was found between age, height and weight with handgrip strength. Regression analysis did not show

\begin{tabular}{llcc}
\multicolumn{4}{l}{$\begin{array}{l}\text { Table 2: Correlations of anthropometric traits } \\
\text { with handgrip strength of } 375 \text { females }\end{array}$} \\
\hline S. no. & Parameter & $\begin{array}{l}\text { Correlation } \\
\text { coefficient }\end{array}$ & p-value \\
\hline 1 & Age & $-0.397\left(^{* *}\right)$ & 0.000 \\
2 & Height & $0.689\left(^{* *}\right)$ & 0.000 \\
3 & Weight & $0.576\left(^{* *}\right)$ & 0.000 \\
4 & BMl $\left(\mathrm{Kg} / \mathrm{m}^{2}\right)$ & $\left.0.302^{* *}\right)$ & 0.000 \\
5 & Fat mass $(\mathrm{kg})$ & $0.458\left(^{* *}\right)$ & 0.000 \\
6 & Fat free mass $(\mathrm{kg})$ & $\left.0.671^{(* *}\right)$ & 0.000 \\
7 & Forearm length $(\mathrm{cm})$ & $0.378\left(^{* *}\right)$ & 0.000 \\
8 & Arm length $(\mathrm{cm})$ & $\left.0.366^{(* *}\right)$ & 0.000 \\
9 & Hand length & $0.406\left(^{* *}\right)$ & 0.000 \\
10 & Hand breadth & $0.466\left(^{* *}\right)$ & 0.000 \\
\hline
\end{tabular}

**Correlation is significant at the 0.01 level (2-tailed)

\begin{tabular}{|c|c|c|c|c|c|}
\hline S.no. & Parameter & B & $\begin{array}{l}\text { Std. } \\
\text { error }\end{array}$ & $T$ & $p$-value \\
\hline 1 & Constant & -12.260 & 1.762 & -6.959 & 0.000 \\
\hline 2 & Age & -0.133 & 0.066 & -21.203 & 0.000 \\
\hline 3 & Height & 0.160 & 0.011 & 14.077 & 0.000 \\
\hline 4 & Weight & 0.132 & 0.006 & 20.544 & 0.000 \\
\hline 5 & Hand breadth & 1.019 & 1.126 & 8.110 & 0.000 \\
\hline
\end{tabular}

significant association of body composition parameters with hand grip strength in this population group. Chatterjee and Chowdhuri 1991 agreed that hand grip strength was positively correlated with weight, height and body surface area. ${ }^{21}$ In other study by Gunther et al 2008 on healthy caucasian adults found that anthropometric variables such as forearm circumference and length, hand size, or body mass showed a positive correlation with grip strength. Body mass index, type of work, and hand dominance showed only a partial positive correlation or no correlation with grip strength. ${ }^{22}$ By using the linear regression to predict the grip strength and calculate the correlation coefficient, the authors derived the following equations $(\mathrm{R}=0.913$, $\mathrm{R}^{2}=0.833$ ) for prediction grip strength in Indian office going females: 
Hand grip $=-12.260-0.13 *$ Age $+0.16 *$ Height $+0.13 *$ Weig ht $+1.02 *$ Hand breadth.

It has to be emphasised that this equation has been developed for Indian office going females whose occupational activity mainly involved computer typing and other desk jobs only.

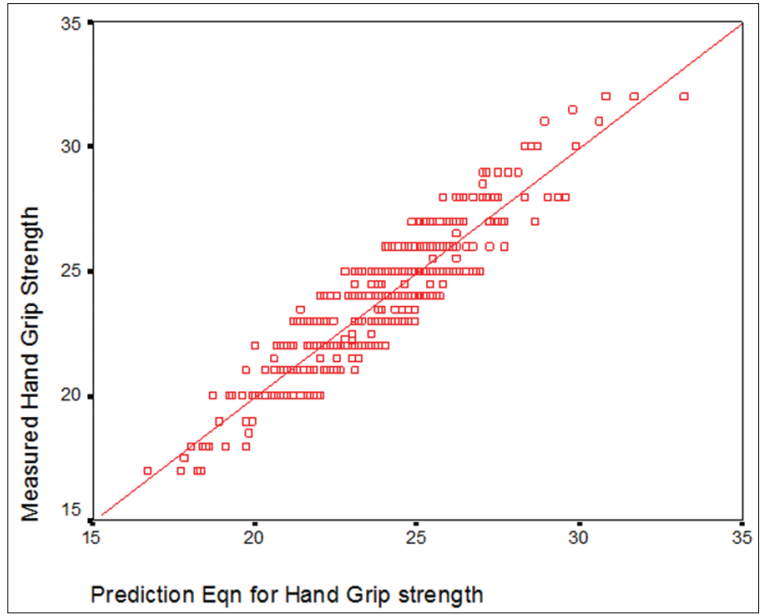

Figure 1: Scatter plot of predicted vs observed handgrip strength

\section{CONCLUSION}

It may be concluded that hand grip strength showed significant association with age and anthropometric measurements (height, weight and hand breadth). Dominant handgrip strength can be predicted in Indian office going females using these anthropometric parameters.

\section{Limitations}

The limitations of the study are that the data may not be transferable to countries or populations with different socioeconomic conditions. The prevalence of high demands on the hand due to occupational activity was low in our study, especially, there were no subjects reporting very high demands. Realistically, the prediction and regression data are only representative and valid for population-based normative values and not for disabled patients. Finally, we did not further examine potentially predictive cofactors such as sporting or leisure activity level. However, there remained little space to explain additional variance since the regression models provided a good fit. One of the strengths of the study is the large representative sample providing valid normative data for

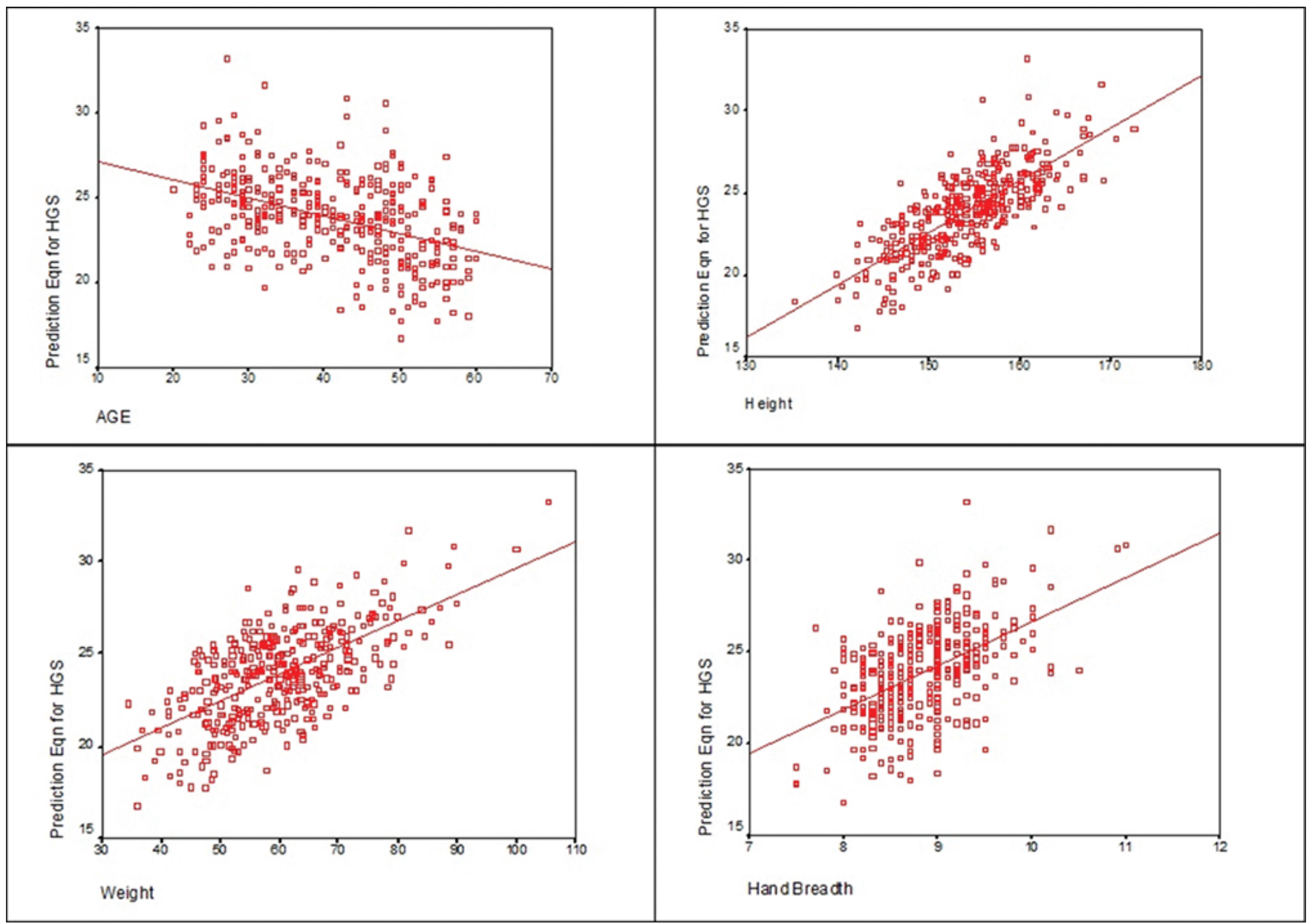

Figure 2: Scatterplot showing correlation of predicted handgrip strength to age, height, weight and hand breadth 
the Indian office going females of different regions of India.

\section{ACKNOWLEDGEMENT}

The authors would like to thank the women participants of this study for their time and effort that enable the completion of this study. Grant for the project was received from DRDO.

\section{REFERENCES}

1. Chandresakaran B, Ghosh A, Prasad C, Krishnan K and Chandrasharma B. Age and anthropometric traits predict hand grip strength in healthy adults. J Hand Microsurg 2010; 2:58-61.

2. Griffith CD, Whyman M and Bassey EJ. Delayed recovery of hand grip strength predicts postoperative morbidity following major vascular surgery. Br J Surg 1989; 76:704-705.

3. Foo LH. Influence of body composition, muscle strength, diet and physical activity on total body and forearm bone mass in Chinese adolescent girls. Br J Nutr 2007; 98:1281-1287.

4. Massy-Westropp N, Rankin W, Ahern M, Krishnan J and Hearn TC. Measuring grip strength in normal adults: reference ranges and a comparison of electronic and hydraulic instruments. J Hand Surg Am 2004; 29:514-519.

5. Nwuga V. Grip strength and grip endurance in physical therapy students. Arch Phys Med Rehab 1975; 56:296-299.

6. Chilima DM and Ismail SJ. Anthropometric characteristics of older people in rural Malawi. Eur J Clin Nutr 1998; 52:643-649.

7. Pieterse $\mathrm{S}$, Manandhar $\mathrm{M}$ and Ismail $\mathrm{S}$. The nutritional status of older Rwandan refugees. Public Health Nutr 1998; 1:259-264.

8. Samson MM, Meeuwsen IB, Crowe A, Dessens JA, Duursma SA and Verhaar HJ. Relationships between physical performance measures, age, height and body weight in healthy adults. Age and Aging 2000; 29: 235-242.

9. Onder G, Penninx BW, Lapuerta P, Fried LP, Ostir GV, Guralnik JM and Pahor M. Changes in physical performance over time in older women: the women's Health and Aging Study. J Geronol Biol Sci Med Sci 2002;57:289-293.
10. Ross $\mathrm{CH}$ and Rösblad $\mathrm{B}$. Norms for grip strength in children aged 4-16 years. A Paediatr 2002; 91:617-625.

11. Singh AP, Koley $S$ and Sandhu JS. Association of hand grip strength with some anthropometric traits in collegiate population of Amritsar. Orient Anthrop 2009; 9:99-110.

12. Koley $S$ and Yadav MK. An association of hand grip strength with some anthropometric variables in Indian cricket players Facta Universitatis, Phy Edu Sport 2009;7(2):113-123.

13. Jurimae $\mathrm{T}$, Hurbo $\mathrm{J}$ and Jurimae $\mathrm{J}$. Relationship of handgrip strength with anthropometric and body composition variables in prepubertal children. J Copmar Hum Biol 2009; 60:225-238.

14. Fleck S, Case S, Puhl J and Van-Handle P. Physical and physiological characteristics of elite women volleyball players. Can J Appl Sport Sci 1985; 10:122-126.

15. Budoff JE. The Prevalence of Rotator Cuff Weakness in Patients with Injured Hands. J Hand Surg 2004; 29:1154-1159.

16. Fry A, Ciroslan D, Fry MD, Leroux CD, Schilling BK and Chiu LZ. Anthropometric and Performance Variables Discriminating Elite American Junior Men Weightlifters. J Strength Cond Res 2006; 4(20):861-866.

17. Smith T, Smith S, Martin M, Henry R, Weeks S and Bryant A. Grip Strength in Relation to Overall Strength and Functional Capacity in Very Old and Oldest Old Females. The Haworth Press Inc 2006:63-78.

18. Di Monaco M, Di Monaco R, Manca M and Cavanna A. Handgrip strength is an independent predictor of distal radius bone mineral density in postmenopausal women. Clin Rheumatol 2000; 19(6):473-476.

19. Lohmann TG, Roche AF and Martorell R. Anthropometric Standardization Reference Manual. Champaign, IL: Human Kinetics Books. 1988.

20. Bohannon RW, Peolsson A, Massy-Westropp N, Desrosiers J and Bear-Lehman J. Reference values for adult grip strength measured with a Jamar dynamometer: a descriptive metaanalysis. Physiotherapy 2006; 92:11-15.

21. Chatterjee $S$ and Chowdhuri BJ. Comparison of grip strength and isometric endurance between the right and left hands of men and their relationship with age and other physical parameters. J Hum Ergol 1991; 20:41-50.

22. Günther CM, Bürger A, Rickert M, Crispin A and Schulz CU. Grip strength in healthy caucasian adults: reference values. J Hand Surg Am 2008; 33(4):558-565.

Authors Contribution:

SR - Concept and design of the study, reviewed the literature, data collection, analysis, manuscript preparation and critical revision of the manuscript; LRV - Concept and design of the study, data collection, analysis and interpretation of data; IS - data collection, analysis and interpretation of data; SC - Drafting manuscript, analysis and interpretation of data; SS - Analysis and interpretation of data.

Source of Support: Defence Research \& Development Organization (DRDO), Ministry of Defence, India, Conflict of Interest: The authors declare that there are no competing interests of any type in relation to the study. 